\title{
REVIEW
}

\section{Targeting Microvasculature for Neuroprotection after SCI}

\author{
Janelle M. Fassbender, ${ }^{1,2,4}$ Scott R. Whittemore, ${ }^{1,3,4}$ and Theo Hagg ${ }^{1,3,5}$ \\ ${ }^{1}$ Kentucky Spinal Cord Injury Research Center, ${ }^{2}$ M.D./Ph.D. Program, ${ }^{3}$ Department of Neurological Surgery, ${ }^{4}$ Department of Anatomical \\ Sciences and Neurobiology, and ${ }^{5}$ Department of Pharmacology and Toxicology, School of Medicine, University of Louisville, Louisville,
} Kentucky 40292

\begin{abstract}
Summary: Spinal cord injury (SCI) is characterized by secondary degeneration, which leads to tissue loss at the epicenter and subsequent functional deficits. This review provides insight into the pathophysiology of microvascular dysfunction and endothelial cell loss, which are among the earliest responses during the first postinjury day. The enigmatic role of the angiogenic response in the penumbra around the lost tissue, which occurs during the first 2 weeks, is also discussed. The importance of stabilizing and rescuing the injured vasculature is now well-recognized,
\end{abstract}

and several pharmacological and genetic treatments have emerged in the past few years. We conclude with suggestions for future experimental research, including development of vascularselective treatments and exploitation of genetic models. In summary, vascular dysfunction following SCI is an important contributor to neurological deficits, as proposed long ago. However, there now appears to be new and potentially powerful opportunities for treating acute SCI by targeting the vascular responses. Key Words: Spinal cord injury, therapeutics, neuroprotection, vasculature, inflammation.

\section{Acute vascular responses contribute to secondary degeneration after SCI}

Following the primary mechanical injury, a secondary injury develops gradually over the first hours to weeks due to disruption in blood flow and progression of detrimental inflammation, leading to white and gray matter loss, cavitation and glial scarring. The concept of the secondary injury in spinal cord injury (SCI) was first hypothesized by Allen [1] in which improvement after spinal cord compression in dogs was enhanced following removal of the hemorrhagic necrotic debris in the lesion epicenter. The good news is that there appears to be a window of opportunity to intervene with therapeutics aimed at minimizing the progression of the secondary injury to limit further loss of function and promote spontaneous recovery. This review will focus on vascular responses in mammals, and the reader is referred to other reviews dealing with other aspects of SCI pathophysiology [2-8].

Electronic supplementary material The online version of this article (doi:10.1007/s13311-011-0029-1) contains supplementary material, which is available to authorized users.

Address correspondence and reprint requests to: Theo Hagg, M.D., Ph.D. Kentucky Spinal Cord Injury Research Center, 511 S. Floyd St., Medical Dental Research Building, Room 616, Louisville, KY 40292.

E-mail: theo.hagg@louisville.edu.
The idea that vascular dysfunction might play a critical role in the pathophysiology of SCI is not new. Following Allen's [9] description of vascular pathology in dogs with contusive SCI, others further characterized various vascular aspects of SCI, including reduced perfusion [10-13]. The earliest formulation of ideas about causation appears to be that "the initial vascular damage and subsequent reparative changes within the spinal cord appear to adequately explain the cavitation observed" [14]. Moreover, it was proposed that "The hypoperfusion of the white matter found in this study suggests that ischemia plays a role in paraplegia resulting from experimental compression injury of the spinal cord" [15]. Thus, the idea that vascular protection would be an important component and viable therapeutic strategy following central nervous system (CNS) injuries was born [4, 6, 16-19]. In comparison to humans, different species show a largely similar vascular and ensuing inflammatory response to SCI $[20,21]$. However, until a more detailed comparison is performed and/or some of the vascular-targeted therapeutic reagents prove to be beneficial in humans, the clinical relevance of the experimental data reviewed here should be viewed as speculative.

Direct physical damage to the spinal cord shears blood vessels within the lesion epicenter causing a central hemorrhage, starting off as small petechial bleeding and 
progressing rostrally and caudally mostly throughout the gray matter [22-24]. The area of this hemorrhagic epicenter was demonstrated by Noble and Wrathall [23] to have a linear relationship with the severity of injury and was further shown to increase in size from $24 \mathrm{~h}$ to 1 week postinjury. Most likely due to its iron-containing hemoglobin, blood is toxic to CNS tissue and is thought to contribute to the necrotic changes following SCI [25].

Direct physical disruption of blood vessels also causes a profound disruption of normal blood flow to the spinal cord [22-24]. Furthermore, vasospasm [26] and loss of autoregulation [27, 28] increase with more severity of post-trauma ischemia [4]. Work in monkeys showed that following SCI, gray matter perfusion was obliterated, whereas white matter perfusion was actually increased, suggesting that white matter degenerates through mechanisms other than ischemia [29]. In fact, microvessel density is relatively low in white matter throughout the CNS compared with gray matter, suggesting that axons and glial cells are less sensitive to ischemia. Blood pressure often drops in injuries higher than $\mathrm{T} 4$, and this is considered to contribute to worse outcomes in humans. Low mean arterial pressure most likely contributes to low spinal cord perfusion and ischemia [30], and thus, vasopressors are acutely administered to support falling mean arterial pressure in patients [31]. One cautionary note for treatment is that reperfusion injury triggered by immediate relief of ischemia and hypoxia can be deleterious to tissue preservation [32]. This vascular dysfunction is a major contributor to the massive death of spinal cord cells, including oligodendrocytes, neurons, astrocytes, precursor cells, and endothelial cells (ECs), which leaves the injury epicenter necrotic.

ECs and blood vessels show degenerative changes within 30 minutes after SCI [33-35] and are lost during the first 3 days [34, 36-38], exacerbating the ischemia (Fig. 1). In the injury penumbra, Casella et al. [34] show that EC death does not correspond to neuronal and glial death; however, the majority of ECs lost are in the injury epicenter causing significant hemorrhage and disruption of vascular autoregulation, and thus is an indirect contributor to neuronal and glial cell death $[4,23,39]$. The EC loss is caused in part by reactive oxygen species and lipid peroxidation of microvasculature $[6,40]$. The hemorrhagic epicenter due to microvascular disruption and EC death is a major cause of the overwhelming presence of free radicals leading to oxidative stress [41, 42]. The activity of lipolytic enzymes increases while antioxidant activity decreases resulting in free radicalinduced lipid peroxidation and subsequent apoptosis of affected cells [43, 44].

Integrin binding to extracellular matrix molecules, such as laminin, is important for attachment and survival of various cells, including ECs $[45,46]$. ECs detach rapidly following SCI $[38,47]$, suggesting that their death might result from lack of integrin stimulation through a process called anoikis. The $\alpha v \beta 3$ integrin promotes EC survival during tumor angiogenesis [48]. Moreover, decreases in angiopoietin 1 (Ang1) following SCI [49], the ligand for the EC-selective receptor Tie2, may also contribute to EC death. Tie2 (Tek) promotes EC survival, stabilizes blood vessels, and reduces leakiness, effects observed during both developmental and adaptive angiogenesis in tumors and experimental CNS pathology [50-58]. Angiopoietin 2 (Ang2), on the other hand, destabilizes blood vessels during angiogenesis and in the absence of vascular endothelial growth factor (VEGF) can contribute to vascular regression and EC death [59]. Although VEGF decreases [49], Ang2 increases following SCI (Gene Expression Omnibus profiles entry GDS2159/1448831_at/Angpt2/Mus musculus) and Ang2 might thus contribute to degenerative changes as well as to the angiogenic responses discussed as follows.

Prolonged repercussions of SCI include permeability $[60,61]$ and the blood spinal cord barrier (BSCB) instability [36, 62] (Fig. 1). The neurovascular unit (NVU) is responsible for maintaining BSCB integrity and constitutes a complex structure within the CNS comprised of ECs, neurons, astrocytes, and pericytes. Investigators continue to unravel the interactions among the cells of the NVU and the therapeutic strategies to target NVU pathology following cerebral and SCI [63, 64]. Pericytes are interesting because they provide structural support and aid in the transmission of small molecules and ions via gap junctions, as well as autocrine and paracrine signaling among ECs, neurons, and astrocytes [65]. They appear to be very important for neuronal structure, function, and overall health [66-68]. Loss of pericytes by 7 days post-SCI may contribute to BSCB instability by loss of direct physical contact and communication via gap junctions [37]. Pericyte death after traumatic brain injury has been shown to be as high as $40 \%$, demonstrating a significant disruption of the NVU following CNS trauma [69]. Therapuetic targeting of pericytes after ischemic stroke has been recognized as another important avenue to support damaged microvessels and prevent neuronal death [70]. The BSCB is formed by the interactions of these cells, as well as the endothelial tight junctions (TJs), in which the occludins, claudins, and junctional adhesion proteins strictly regulate flow of cells and molecules into the CNS. In the normal animal, the functional properties of each family of $\mathrm{TJ}$ components and the selective leakiness of the CNS TJs are well-studied [71, 72]. How these processes are disrupted following traumatic and ischemic CNS microvascular injury is a topic under current investigation $[36,62,73]$.

Perfusion of damaged and/or immature vessels causes excessive permeability due to dysfunctional TJs $[3,36,37]$ (Fig. 1) and can result in functional consequences when 
paired with an acute stressor, such as exercise [74]. Disruption of these junctional proteins results in BSCB instability and increased permeability up to 21 days in the mouse and 28 days in the rat $[36,62]$. Upregulation of matrix metalloproteinases results in excessive extracellular matrix (ECM) digestion, increased inflammation, and uncontrolled vascular permeability [75]. BSCB pathology plays a major role in secondary injury by promoting edema and inflammatory infiltration and by providing CNS access to potentially neurotoxic molecules [76]. As demonstrated by Nagy et al. [77, 78], cationic changes in the luminal endothelial glycocalyx increases cerebral permeability to macromolecules, such as horseradish peroxidase. Changes in the glycocalyx post-SCI increases cation content and is an important indicator of EC phenotype and BSCB stability [61]. Lectins are used to define these changes as a means to identify injured or reactive microvessels. For instance, the lectin IB4 binds only a subset of proliferative microvessels maximally at $7 \mathrm{dpi}$, which illustrates that phenotypic changes in the EC glycocalyx are functionally relevant
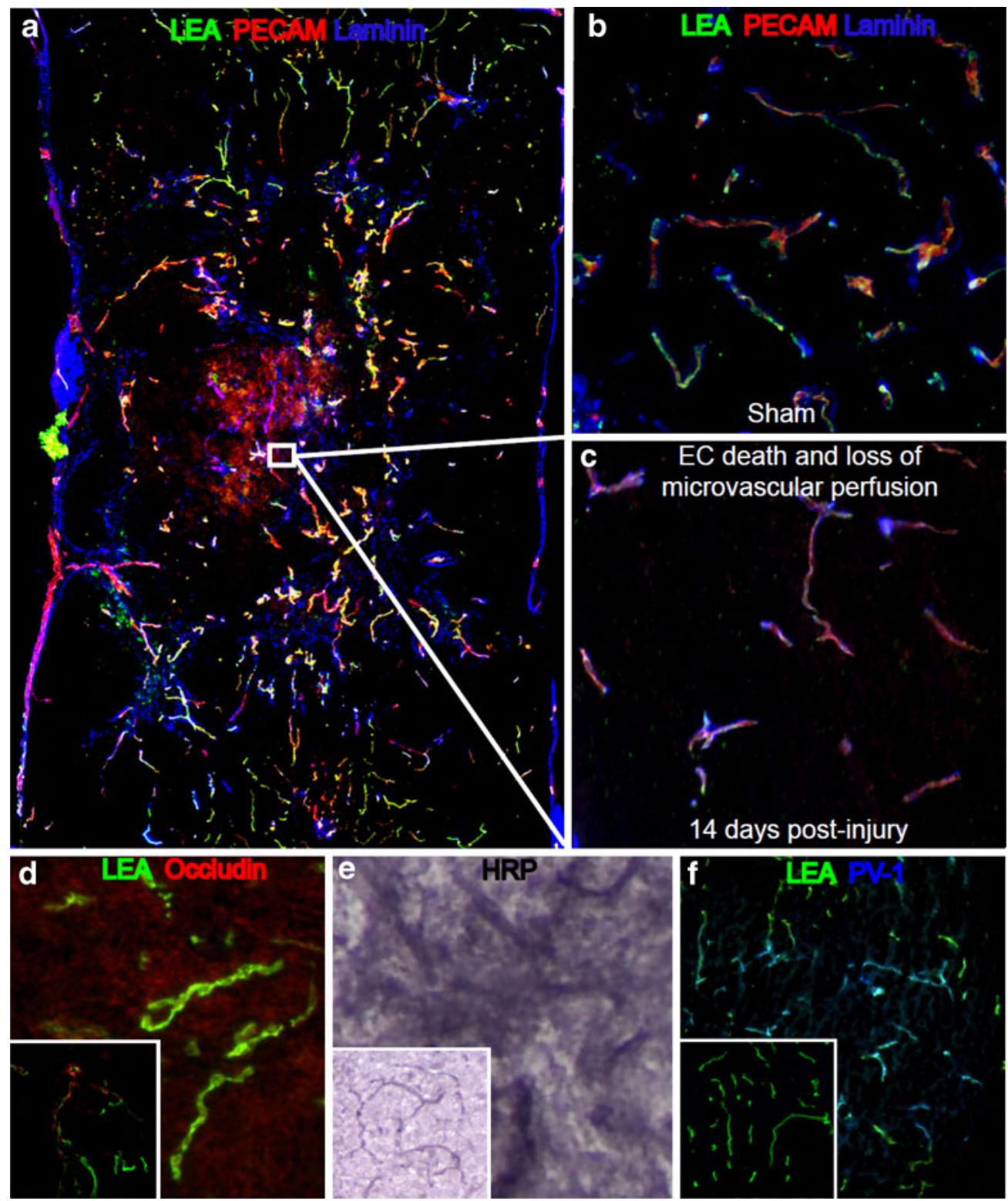

FIG. 1. (a) Fourteen days following traumatic $\mathrm{SCl}$, mechanical disruption of microvessels (box indicates site of microvascular loss displayed in [c]), and endothelial cell (EC) death has resulted in spinal cord hypoxia, and (c) loss of adequate microvascular perfusion compared to the sham spinal cord (b). (d) The neurovascular unit having lost appropriate tight junctional proteins, such as occludin, (e) becomes permeable to large proteins such as horseradish peroxidase (HRP). (f) Microvascular dysregulation is further evidenced by expression of plasmalemmal vesicle-associated protein (PV-1), a marker of fenestrated capillaries. Insets in (D-F) show sham spinal cord microvessels. $\mathrm{LEA}=$ Lycopersicon esculentum (tomato) agglutinin; PECAM = platelet endothelial cell adhesion molecule. 
Table 1. Therapeutics Leading to Tissue Sparing and Functional Recovery with an Additional Vascular Component in Animal Models of Traumatic SCI

\begin{tabular}{|c|c|c|c|}
\hline Target & Treatment & Outcome & Study reference numbers \\
\hline \multicolumn{4}{|l|}{ Vascular protection } \\
\hline Spinal cord perfusion & Nimodipine plus vasopressor & $\begin{array}{l}\text { Blood flow and axon conduction } \uparrow \text {, } \\
\text { function modest } \uparrow\end{array}$ & {$[30,91,92]$} \\
\hline Oxidative damage & Tirilazad, selenium, tempol & Blood flow $\uparrow$, stabilized BSCB & [93-95] \\
\hline Heme oxygenase- 1 & Genetic HO-1 knockdown, hemin & Inflammation $\downarrow$, Stabilized BSCB & {$[42,96]$} \\
\hline Nonselective ion channels & $\mathrm{KO}$, antisense knockdown & Hemorrhage $\downarrow$ & [97-99] \\
\hline Tie 2 and $\alpha v \beta 3$ integrin & C16 peptide and angiopoietin 1 & $\begin{array}{c}\text { Vascular density } \uparrow \text {, inflammation } \downarrow \text {, } \\
\text { permeability } \downarrow\end{array}$ & {$[83]$} \\
\hline Tie2 and VEGFR & AAV-VEGF and AAV-Ang-1 & $\begin{array}{l}\text { MRI lesion volume } \downarrow \text {, MRI detected } \\
\text { vascular stabilization }\end{array}$ & {$[100]$} \\
\hline $\begin{array}{l}\text { Protein tyrosine phosphatases } \\
\text { Angiogenesis }\end{array}$ & Small molecule inhibitor (bpV[phen]) & Vascular density $\uparrow$, apoptosis $\downarrow$ & {$[101]$} \\
\hline VEGFR & $\begin{array}{l}\text { ZFP-VEGFA transcription factor; } \\
\text { VEGF-producing neural stem cells }\end{array}$ & Vascular density $\uparrow$, apoptosis $\downarrow$ & {$[102,103]$} \\
\hline Semaphorin $3 \mathrm{~A}$ & Small molecule inhibitor (SM-216289) & Vascular density $\uparrow$ & {$[104]$} \\
\hline Notch & Agonist & Vascularity $\downarrow$, maintained perfusion & {$[105]$} \\
\hline c-Met & Hepatocyte growth factor & Vascular density $\uparrow$ & {$[106]$} \\
\hline$\alpha \mathrm{v} \beta 3$ integrin & C16 integrin agonist & Vascular density $\uparrow$ & {$[107]$} \\
\hline CXCL10 & Anti-CXCL10 antibody & Vascular density $\uparrow$ & [108] \\
\hline Cell therapy & IV $\mathrm{CD}_{133^{+}}$cells & Vascular density $\uparrow$ & {$[107]$} \\
\hline
\end{tabular}

AAV-Ang-1 = adeno-associated virus-Ang-1; AAV-VEGF = adeno-associated virus-VEGF; BSCB = blood-spinal cord barrier; CXCL10 = C-X-C motif chemokine 10; $\mathrm{MRI}=$ magnetic resonance image; $\mathrm{SCI}=$ spinal cord injury; VEGFR = VEGF receptor; ZFP-VEGFA = zinc finger protein VEGF isoform A.

[37]. Plasmalemmal vesicle-associated protein, a species-conserved protein marker of fenestrated endothelium, also specifically marks ECs undergoing pathological transformation after SCI [79] (Fig. 1). Microvascular permeability is a key factor in spinal cord inflammation and edema. Due to the restricted space within the bony spinal canal, edema further exacerbates the ischemic injury. However, it is still debated whether early or late decompression in humans is beneficial [80].

The degree of white matter-sparing correlates to longterm preservation of locomotor function [81]. Thus, the mechanisms of contributing white matter loss are of great interest. White matter loss ensues during the subacute phase, partially due to activation of FAS and p75 receptors, which triggers apoptosis of glial cells [82]. The finding that the number of blood vessels correlates with white matter-sparing at 7 days postinjury [83] suggests that maintenance of vascular function is a good target for improving function of long-projecting fiber tracts, which are essential for motor and sensory function. The mechanisms involved in this apparent relationship are unknown but may involve reduced inflammation. The inflammatory response following SCI is clearly involved in white matter damage [8, 84], but the molecular vascular mechanisms involved in the recruitment of detrimental leukocytes require further investigation. Mechanical disruption of endothelial basement membranes promotes infiltration of inflammatory cells [85].

Although astrocytes are understudied within the realm of the vascular responses, their primary role may be to reduce leukocyte trafficking and promoting BSCB repair, and thereby functional recovery [86-88].

\section{Treatments targeting acute vascular responses following SCI}

Six neuroprotective agents have been taken as far as phase III clinical trials [89], including methylprednisolone, naloxone, tirilazad mesylate, monosialoganglioside GM1, 4-aminopyridine, and tizanidine. Yet, none of these showed efficacy for their primary endpoint and none are approved by the Untied States Food and Drug Administration (FDA) for SCI. Currently, the only neuroprotective treatment for SCI is methylprednisolone, but its use is controversial and its efficacy is debatable [90]. We, and others, have recognized that targeting of the vascular responses might change this dire picture. Several discoveries during the last decade of the molecular mechanisms involved in vascular dysfunction have led to a growing arsenal of experimental treatments. The studies presented in Table 1. have demonstrated enhanced functional angiogenesis or vascular protection along with improvements in tissue-sparing and/or locomotor behavior signifying the clinical potential of a vascular therapeutic for SCI. Interestingly, several studies that show tissue-sparing and functional recovery also report improved vascularity with attenuated inflammation or improved vascularity with decreased apoptosis. Stabilization of the BSCB, as measured by large molecule extravasation postinjury, is another important indicator of vascular protection.

As discussed, low blood pressure contributes to inadequate spinal cord perfusion. Treatment with the 
CNS vasodilator nimodipine plus systemic vasopressors, such as adrenaline or volume expansion, but not individually, can maintain spinal cord blood flow and axonal conduction during the acute injury phase in rats $[30,91]$. However, this is only accompanied by a moderate functional improvement [92]. One of the underlying problems is the damage and death of ECs caused in part by reactive oxygen species and lipid peroxidation of microvasculature [6, 40], perhaps formed due to reperfusion injury [32]. In fact, treatments with the steroid tirilazad, antioxidants, or selenium maintain spinal cord blood flow and reduce leakage following contusive SCI [93, 95, 109]. Peroxynitrite-induced oxidative damage following SCI can be reduced by the nitroxide antioxidant Tempol [110]. The treatment has to be initiated within the first hour, perhaps consistent with a role for peroxynitrites in reperfusion injury to ECs. Heme-oxygenase (HO) is also a target for antioxidant intervention. HO reduces oxidative injury by catalyzing the conversion of the oxidant heme to the antioxidant biliverdin. $\mathrm{HO}-1$ is the inducible form and is protective following SCI [42]. The pharmacological drug, hemin, induces HO-1 and is neuroprotective following SCI [96]. Hemin has already been approved by the FDA as an intravenous treatment for porphyria. Of interest is the fact that HO1 activity is stimulated by endoplasmic reticulum stress in vascular smooth muscle cells (VSMCs) [111], suggesting possible connections among these therapeutic interventions and further exemplifying the need to investigate the roles of VSMCs and pericytes in SCI recovery.

Membrane channels also provide targets for therapeutic compounds. ECs greatly increase expression of sulfonylurea receptor 1 (SUR1)-regulated $\mathrm{NC}_{\mathrm{Ca}-\mathrm{ATP}}$ channels, such as transient receptor potential cation channel subfamily $M$ member 4 (Trpm4), and this contributes to the temporal and spatial expansion of secondary damage after SCI [98]. SUR1 is also newly expressed in humans with SCI, making this system a relevant target [97]. Due to ATP depletion in the ischemic spinal cord, channels like Trpm4 open, which causes depolarization leading to edema and EC death. Inhibition of SUR1 by genetic knockout or by treatment with antisense reduces microvascular fragmentation, hemorrhage, white matter loss, and functional deficits in rats and mice with cervical hemi-contusion injuries [97, 98]. The antisense is probably more efficacious than pharmacological inhibitors because it is expected to reduce the de novo expression. Trpm4 inhibition by either knockout in mice or antisense in rats has a similar neuroprotective effect [99]. Of note is that glibenclamide and repaglinide are both FDA-approved drugs for type II diabetes, and they also have such neuroprotective properties following SCI [98]. Glibenclamide is a sulfonylurea inhibitor that binds to SUR1 and repaglinide is known to block $\mathrm{K}_{\mathrm{ATP}}$ channels.

To our knowledge, no published studies have attempted to selectively reduce hemorrhage and the toxicity of hemorrhagic blood, but it is possible that the antioxidants also reduce the toxicity of blood. There is likely a very fine line in trying to reduce bleeding and maintain spinal cord perfusion.

Among the most direct support for the idea that EC dysfunction and death play a prominent role in secondary degeneration after SCI follows from work targeting the Tie2 receptor, which is almost exclusively present in ECs [112, 113]. Intravenous injections of Ang1 during the first week following a contusive SCI reduces white matter loss, inflammation, and locomotor deficits [83]. This is consistent with the known pro-survival role of Ang1 for ECs [50, 52, 114, 115] and the finding that Ang1 levels decrease following SCI [100]. The antiinflammatory effects may be due to its known downregulation of ICAM1, which is necessary for leukocyte binding [116]. Importantly, the treatment can be given with a 4-h delay, which would be sufficient time to make a diagnosis in human SCI cases and to allow the start of intravenous infusions.

As discussed, the $\alpha \mathrm{v} \beta 3$ integrin also contributes to EC survival. Integrins have a reciprocal interaction with growth factor receptors [117], and both $\alpha \mathrm{v} \beta 3$ integrin and Tie2 can activate the PI3K-Akt pathway in ECs [118, 119]. This may explain why a combined intravenous treatment with Ang1 and an $\alpha \mathrm{v} \beta 3$ integrin peptide agonist named $\mathrm{C} 16$ was even more effective in reducing the detrimental outcomes of contusive SCI in mice [83]. We have also shown that Ang-1 reduces permeability at $72 \mathrm{~h}$ following SCI [83], most likely via the capacity of Ang-1 to preserve the integrity of EC tight junctions under pathological conditions [58, 120]. Others have also seen the BSCB stabilizing effects of Ang1 and that a combination of VEGF and Ang1 leads to improved functional recovery [100].

Finally, protection of ECs by a broad spectrum, selective protein tyrosine phosphatase (PTP) inhibitor also seems to result in protection of long-projecting axons [101]. PTPs are known to inhibit tyrosine kinase growth factor receptors and their downstream intracellular signaling tyrosine kinases. It remains to be determined which mechanisms underlie the PTP inhibition effects and whether this might include facilitating Tie2 signaling.

\section{Adaptive angiogenesis following SCI}

Angiogenesis is the development of new vessels from pre-existing capillaries whereas vasculogenesis is primarily an embryonic event in which angioblasts form the 
primordial vasculature [121]. Following contusive SCI, new blood vessels form at the epicenter and in the penumbra most likely through angiogenesis during days 3 to 14 postinjury [17, 34, 36, 37, 39]. Additionally, circulating angioblasts might contribute to vessel formation during the reparative phase as they do in other systems [122-124]. Vascular repair may also be affected by hemodynamics $[122,125]$, suggesting that continued preservation of spinal cord blood flow throughout extended times postinjury would be beneficial. Angiogenesis in the CNS is unique, in that during CNS vascular development, rapid vessel production depends on high numbers of angiogenic sprouts with long filopodia instead of the intussusception seen in peripheral vascular beds [122]. Whether the same is true following SCI or whether this can be exploited to develop targeted therapies is unknown.

The angiogenic response has been viewed as a vital process that occurs following pathological and traumatic processes, such as SCI to support regenerating or spared tissue $[18,19,126]$. Despite a $75 \%$ loss of ECs in the first hour following contusive rodent $\mathrm{SCI}$, a robust angiogenic response begins during the first week after injury $[17,34$, 127]. In the rat, a net vascular regression occurs as cystic cavitation develops during the second week postinjury [17, 126], whereas vascular density reaches $70 \%$ of control values by 14 days in the mouse [36, 37]. IB4 binds to a subset of proliferative microvessels at 7 days postinjury [37]. Other markers for angiogenic microvessels are $\alpha 1 \beta 1$ integrin [128] and ADAM8 [129], which increase dramatically at the epicenter following SCI and co-localize with IB4. Molecules that play a role in EC migration, such as MMP14, are also found at the injury site [129]. The new vasculature is not necessarily beneficial as they may be of the fenestrated, "leaky" type as indicated by their expression of plasmalemmal vesicle-associated protein [79].

Angiogenic blood vessels are thought to be leaky, and therefore the question is whether such vessels are beneficial or detrimental. In our recent study, we did observe a correlation between the increased number of vessels at 7 days postinjury and locomotor function in mice treated with $\mathrm{C} 16$ peptide [83]. C16 alone did not reduce permeability, suggesting that despite greater permeability, new blood vessels are beneficial. This is supported by the improved function seen in rats treated with VEGF, whereas the permeability at the epicenter was increased [130]. However, other studies have shown VEGF treatment to be ineffective after SCI [131], or detrimental [132].

An additional consideration for therapeutic targeting of the vasculature is remodeling, which stabilizes and matures postangiogenic microvessels [133]. Therapies targeting newly formed microvessels that have not properly undergone vascular remodeling can be tested in vitro and ex vivo [133, 134], and have been shown to be beneficial in tumor angiogenesis [135]. Mural cell recruitment as one aspect of vascular remodeling and maturation is an important consideration in the CNS. Astrocytes, pericytes, and VSMCs are integral components of the BSCB, as well as contributing to vessel maturation. An important illustration of this is the syndrome cerebral autosomal dominant arteriopathy with subcortical infarcts and leukoencephalopathy caused by mutations in Notch 3, expressed on VSMCs [136]. Cerebral autosomal dominant arteriopathy with subcortical infarcts and leukoencephalopathy is the predominant genetic cause of ischemic stroke and an important model of vascular dementia [137]. Progressive deterioration of VSMCs and accumulation of granular osmiophilic material in the VSMC basement membrane are characteristic of the disease [138], which disrupts vascular mechanotransduction causing permanent vasodilation, pooling, and ischemia [137]. In the normal spinal cord, desmin-positive pericytes are detected at vascular branch points, but by 7 days postinjury they are largely absent [37]. Thus, pericytes and VSMCs are additional mediators of CNS blood flow that are important to consider as a vascular therapeutic targeting the injured spinal cord. Such mechanisms have yet to be exploited therapeutically.

\section{Therapeutic Angiogenesis?}

It is possible that not all microvessels can be rescued following SCI. It follows from what was previously described that manipulation of sprouting angiogenesis and vascular remodeling should aim at creating a mature, well-perfused microvasculature, but this phenomenon is complex and not well understood in the realm of SCI.

VEGF has been a frequent vascular target in animal studies for several reasons. VEGF is a potent mediator of angiogenesis and vascular permeability, and is upregulated within the lesion epicenter acutely following SCI $[139,140]$. The application of VEGF in SCI is a matter of debate and investigators have found apparently conflicting evidence. Intraparenchymal application of VEGF $_{165}$ in the lesion epicenter of rats increases both vascular permeability by 24 -h post-SCI and exacerbates the loss of both white and gray matter [132]. Formally known as vascular permeability factor, VEGF increases vascular permeability when administered acutely as seen by magnetic resonance imaging, although it improves function [130]. On the other hand, $V_{E G F} 165$ intraparenchymal injection has resulted in significantly increased hind limb locomotor scores, indicating alleviation of secondary damage [141]. Other methods of VEGF treatment include intraparenchymal injection of a zinc finger protein transcription factor designed to activate expression of all isoforms of endogenous VEGF-A [102]. This resulted in enhanced vascularity and better tissue sparing and function. Transplanted neural stem cells 
secreting VEGF have also enhanced the spontaneous angiogenic response and have shown beneficial effects [103]. Yet others have found only limited effects of repeated VEGF treatments [131].

Sema3A inhibition with a small molecule is also accompanied by better vascularity and outcomes following SCI [96, 101, 102, 104]. Sema3A shares the neuropilin 1 receptor with VEGF and competitively antagonizes VEGF165 binding. Thus, it is possible that the Sema3A inhibitor enhances endogenous VEGF signaling and angiogenesis. The interpretation of the study is complicated by the lack of showing angiogenesis (an increase compared with earlier times or to normal) and the fact that Sema3A was found on fibroblasts and neuropilin-1 is typically found on axons.

To address the issue of enhanced permeability due to VEGF treatment, Herrera et al. [100] have shown that cotreatment with Ang1 via intraparenchymal infection with adeno-associated virus (AAV) vectors immediately following SCI further improves outcomes. This is consistent with the role of Ang-1 in establishing and maintaining vascular maturation, stabilization, and integrity $[50,52,56]$.

Post-SCI dysregulation of VEGF or an inappropriate VEGF gradient would be an important factor in downstream Notch signaling. VEGF receptor 2 activation results in increased Notch signaling, returning ECs to a nonangiogenic state $[142,143]$, probably because ECs with high Notch expression become quiescent stalk cells $[144,145]$. Thus, application of a Notch pharmacological agonist in addition to exogenous VEGF may enhance its protective effects while controlling deleterious increases in vessel permeability. Intravenous administration of a Notch agonist decreases penumbral microvascular density in the gray matter while maintaining perfusion [105]. This suggests that the VEGF-Notch interaction is complex and difficult to therapeutically target.

$\mathrm{C}$-met via its ligand hepatocyte growth factor is a known angiogenic pathway, activated by growing tumors and targeted in potential anti-cancer therapies [146]. $\mathrm{C}$-met signaling also regulates angiogenesis in porcine aortic EC line and proliferation and migration in human umbilical vein endothelial cells (HUVECs) by VEGF induction [147, 148]. Potential exploitation of c-met signaling to promote angiogenesis has been studied in models of ischemic stroke and SCI [106, 149]. Enhanced locomotor recovery and decreased lesion volume was observed with spinal cord intraparenchymal pre-treatment of hepatocyte growth factor, with significantly diminished apoptosis of oligodendrocytes and neurons and increased new microvessel formation [106]. Although interesting, these results would obviously need to be observed in a clinically relevant model in which cmet signaling was activated post-SCI.

The $\alpha \mathrm{v} \beta 3$ integrin is known to play a role in angiogenesis [48] and the $\mathrm{C} 16 \alpha_{\mathrm{v}} \beta 3$ integrin agonist promotes angiogenesis in the chick chorioallantoic membrane assay $[150,151]$. Our own studies also suggest that this is the case following SCI as C16 treated injured mice had more perfused blood vessels at the epicenter at 7 days than at 1 day postinjury [83]. Co-treatment with Ang1 did not seem to inhibit the effects of $\mathrm{C} 16$.

Inhibition of the cytokine $\mathrm{C}-\mathrm{X}-\mathrm{C}$ motif chemokine 10 (CXCL10) promotes upregulation of angiogenic factors resulting in increased density of blood vessels. Although there is significant tissue sparing in anti-CXCL10 antibody-treated animals, the functional implications of this result is unknown [108]. Nevertheless, subsequent studies by the same investigators have revealed decreased apoptosis and increased axonal sparing, further suggesting potential therapeutic benefit [152].

An additional less well-explored approach to target the vascular compartment post-SCI is cellular therapy. Sasaki et al [107] used granulocyte stimulating factor to mobilize and iscolate CD133+ cells for transplantation post-SCI. The CD133+ cells are a subtype of CD34+ endothelial precursors that effect not only angiogenesis but also secrete CNS growth factors and cytokines [153], and when administered to the spinally injured rat, improve locomotor recovery [107].

\section{Future directions}

As previously discussed, endothelial targeting of SCI therapies has shown tremendous promise, particularly the neuroprotective efforts during the acute phase. The clear advantage of targeting the microvasculature is the easy, rapid, and direct manner that intravenous drug delivery poses. We are increasingly able to understand the complexities of the vascular responses and the still limited extent to which vasculature can be protected with current experimental and FDA-approved drugs. Thus, a better understanding both how to maximally protect the damaged vasculature and how angiogenesis contributes to recovery of traumatically injured spinal tissue is an essential topic of further research.

Also, as previously discussed, current options for manipulating angiogenic responses after SCI are limited to available pharmacological agents. However, from a translational standpoint, these therapies will be the easiest to move into clinical trials in SCI. We contend that testing drugs that are FDA-approved for other applications for their angiogenic and/or vasoprotective properties after SCI may be the most fruitful approach. The vasoprotective potential of existing drugs can be readily tested in short in vivo assays, as most microvessels at the epicenter are dead, nonperfused or dysfunctional 1 day following contusive or compressive SCI.

With respect to understanding molecular mechanism(s) underlying angiogenic responses and their effects on the recovery of function after SCI, mouse models have the 
most promise. Transgenic mouse reporter models in which transgenes are specifically and potentially temporally expressed in ECs could help in analyses or purification of ECs. Such genes can be over expressed or conditionally deleted in ECs. The EC-specific receptor tyrosine kinase tie 2 has been used to drive expression of lacZ [154] and enhanced green fluorescent protein (EGFP) [155] in the mouse. The one caveat to using the Tie2-GFP mice is that EGFP expression is high in arterial vessels and much weaker in venous vessels (J.B. Hoying, personal communication). Tie2-GFP transgenic rats have also been developed [156]. The advantage of these models is that transgene expression is observed only in the vasculature. One potential problem to control for is the fact that Tie2 can also be expressed by a subclass of pro-angiogenic monocytes [157] and by hematopoietic stem cells [158]. Although these reporters have not been used in SCI models to date, their potential to directly observe vascular responses (either in real time with 2-photon optics or histologically) after SCI is clear. An alternative mouse model is to use the universal reporter ROSA-enhanced yellow fluorescent protein gene (EYFP) mouse [159], which contains an EYFP inserted into the Gt(ROSA)26Sor locus. Expression of EYFP is blocked by an upstream loxP-flanked STOP sequence. When bred to mice with a cre recombinase gene under the control of a promoter of interest, the STOP sequence of the targeted gene is deleted in the tissue of interest, and EYFP expression is observed. If these mice are crossed with a mouse expressing cre under the control of the EC-specific vascular endothelial-cadherin promoter [160], all vasculature will express EYFP. Crossing these cre mice with $\operatorname{lox} P$ mice of any gene of interest could produce interesting models for investigating the role of those genes in EC behaviors. Using available tamoxifeninducible Vascular endothelial-cadherin-CreER ${ }^{\mathrm{T} 2}$ [161] or Tie2ER ${ }^{\mathrm{T} 2}$ [162] mice would enable temporal induction of both floxed reporter and/or transgenes, specifically in the vasculature. Studies using these mice would be valuable from a therapeutic standpoint, as a means to identify novel target genes and/or proteins for development of future pharmacological effectors.

Vascular protection and angiogenesis may also become an important vehicle for axonal regeneration as neovessels have been observed to exert a potent growth stimulating action on axonal sprouting [163]. Not only do spinal cord microvessels support neural parenchyma by providing adequate blood supply and oxygenation, but the CNS endothelium actively secretes neurotrophins such as BDNF that have been shown to support regenerating spinal cord tissue [64, 164]. In addition, the basement membrane of CNS blood vessels contain ECM molecules like laminin, which have guidance properties. Indeed, regenerating axons have been shown to follow newly formed blood vessels after SCI [17].
Given the central role of vascular dysfunction and the potential of vascular targeting treatments for SCI, there is a great need to develop noninvasive vascular outcome measures, including imaging and biomarkers. It is expected that vascular assessment will be needed for both for diagnostic purposes and for the assessment of therapeutic efficacy. One of the imaging problems that needs to be to resolved is the limited resolution of current technology and the very small dimensions of the mouse and rat spinal cord. This is also still challenging for techniques, such as positron emission tomography, when considering the human spinal cord.

Finally, our studies and the studies of others are currently and continue to be directed by what we learned from the cancer and cardiovascular fields. We have realized that the detrimental and beneficial inflammatory components of SCI are heavily dependent on the status of the microvasculature, and we foresee that the immunology field will help us develop more advanced vascular targeting therapies for SCI.

Acknowledgments: This work was supported by the National Institutes of Health, grant numbers F30 1F30NS064669 (JMF), NS045734, RR15576; the Norton Healthcare, and the Commonwealth of Kentucky Challenge for Excellence (S.R.W., T.H.). Full conflict of interest disclosure is available in the electronic supplementary material for this article.

\section{REFERENCES}

1. Allen A. Surgery of experimental lesion of spinal cord equivalent to crush injury of fracture dislocation of spinal column. A preliminary report. JAMA 1911;57:878-880.

2. Popovich P, McTigue D. Damage control in the nervous system: beware the immune system in spinal cord injury. Nat Med 2009; $15: 736-737$.

3. Mautes AE, Weinzierl MR, Donovan F, Noble LJ. Vascular events after spinal cord injury: contribution to secondary pathogenesis. Phys Ther 2000;80:673-687.

4. Tator $\mathrm{CH}$, Fehlings MG. Review of the secondary injury theory of acute spinal cord trauma with emphasis on vascular mechanisms. J Neurosurg 1991;75:15-26.

5. Hagg T, Oudega M. Degenerative and spontaneous regenerative processes after spinal cord injury. J Neurotrauma 2006;23:264-280.

6. Hall ED, Springer JE. Neuroprotection and acute spinal cord injury: a reappraisal. NeuroRx 2004;1:80-100.

7. Bramlett HM, Dietrich WD. Progressive damage after brain and spinal cord injury: pathomechanisms and treatment strategies. Prog Brain Res 2007;161:125-141.

8. Alexander JK, Popovich PG. Neuroinflammation in spinal cord injury: therapeutic targets for neuroprotection and regeneration. Prog Brain Res 2009;175:125-137.

9. Allen AR. Remarks on the histopathological changes in the spinal cord due to impact. An experimental study. J. Nerv. Ment. Dis 1914;41:141-147.

10. Schneider RC, Crosby EC. Vascular insufficiency of brain stem and spinal cord in spinal trauma. Neurology 1959;9:643-656.

11. Tonnis D. [Spinal cord trauma and circulatory insufficiency. Studies on the pathogenesis of traumatic spinal cord lesions and the symptoms of insufficiency of spinal circulation]. Beitr Neurochir 1963;5:1-167.

12. Wolman L. The disturbance of circulation in traumatic paraplegia in acute and late stages: a pathological study. Paraplegia 1965;2:213226. 
13. Kamiya T. Experimental study on anterior spinal cord compression with special emphasis on vascular disturbance. Nagoya J Med Sci 1968;31:171-190

14. Wagner FC Jr., Van Gilder JC, Dohrmann GJ. The development of intramedullary cavitation following spinal cord injury: an experimental pathological study. Paraplegia 1977;14:245-250.

15. Means ED, Anderson DK, Nicolosi G, Gaudsmith J. Microvascular perfusion experimental spinal cord injury. Surg Neurol 1978;9:353-360.

16. Zhang Z, Krebs CJ, Guth L. Experimental analysis of progressive necrosis after spinal cord trauma in the rat: etiological role of the inflammatory response. Exp Neurol 1997;143:141-152.

17. Loy DN, Crawford CH, Darnall JB, Burke DA, Onifer SM, Whittemore SR. Temporal progression of angiogenesis and basal lamina deposition after contusive spinal cord injury in the adult rat. J Comp Neurol 2002;445:308-324.

18. Facchiano F, Fernandez E, Mancarella S, et al. Promotion of regeneration of corticospinal tract axons in rats with recombinant vascular endothelial growth factor alone and combined with adenovirus coding for this factor. J Neurosurg 2002;97:161-168.

19. Goldsmith HS. The evolution of omentum transposition: from lymphedema to spinal cord, stroke and Alzheimer's disease. Neurol Res 2004;26:586-593.

20. Norenberg MD, Smith J, Marcillo A. The pathology of human spinal cord injury: defining the problems. J Neurotrauma 2004;21: 429-440.

21. Fleming JC, Norenberg MD, Ramsay DA, et al. The cellular inflammatory response in human spinal cords after injury. Brain 2006;129(Pt 12):3249-3269.

22. Tator CH. Review of experimental spinal cord injury with emphasis on the local and systemic circulatory effects. Neurochirurgie 1991;37:291-302.

23. Noble LJ, Wrathall JR. Correlative analyses of lesion development and functional status after graded spinal cord contusive injuries in the rat. Exp Neurol 1989;103:34-40.

24. Beggs JL, Waggener JD. The acute microvascular responses to spinal cord injury. Adv Neurol 1979;22:179-189.

25. Sadrzadeh SM, Anderson DK, Panter SS, Hallaway PE, Eaton JW. Hemoglobin potentiates central nervous system damage. J Clin Invest 1987;79:662-664.

26. Anthes DL, Theriault E, Tator CH. Ultrastructural evidence for arteriolar vasospasm after spinal cord trauma. Neurosurgery 1996;39:804-814.

27. Smith AJ, McCreery DB, Bloedel JR, Chou SN. Hyperemia, CO2 responsiveness, and autoregulation in the white matter following experimental spinal cord injury. J Neurosurg 1978;48:239-251.

28. Senter HJ, Venes JL. Loss of autoregulation and posttraumatic ischemia following experimental spinal cord trauma. J Neurosurg 1979;50:198-206.

29. Bingham WG, Goldman H, Friedman SJ, Murphy S, Yashon D, Hunt WE. Blood flow in normal and injured monkey spinal cord. J Neurosurg 1975;43:162-171.

30. Guha A, Tator CH, Smith CR, Piper I. Improvement in posttraumatic spinal cord blood flow with a combination of a calcium channel blocker and a vasopressor. J Trauma 1989;29:1440-1447.

31. Vale FL, Burns J, Jackson AB, Hadley MN. Combined medical and surgical treatment after acute spinal cord injury: results of a prospective pilot study to assess the merits of aggressive medical resuscitation and blood pressure management. J Neurosurg 1997; 87:239-246.

32. Guth L, Zhang Z, Steward O. The unique histopathological responses of the injured spinal cord. Implications for neuroprotective therapy. Ann N Y Acad Sci 1999;890:366-384.

33. Griffiths IR, Burns N, Crawford AR. Early vascular changes in the spinal grey matter following impact injury. Acta Neuropathol 1978;41:33-39.

34. Casella GT, Bunge MB, Wood PM. Endothelial cell loss is not a major cause of neuronal and glial cell death following contusion injury of the spinal cord. Exp Neurol 2006;202:8-20.

35. Dohrmann GJ, Wick KM. Demonstration of the microvasculature of the spinal cord by intravenous injection of the fluorescent dye, thioflavine S. Stain Technol 1971;46:321-322.

36. Whetstone WD, Hsu JY, Eisenberg M, Werb Z, Noble-Haeusslein LJ. Blood-spinal cord barrier after spinal cord injury: relation to revascularization and wound healing. J Neurosci Res 2003; 74:227-239.

37. Benton RL, Maddie MA, Minnillo DR, Hagg T, Whittemore SR. Griffonia simplicifolia isolectin B4 identifies a specific subpopulation of angiogenic blood vessels following contusive spinal cord injury in the adult mouse. J Comp Neurol 2008;507:1031-1052.

38. Koyanagi I, Tator CH, Lea PJ. Three-dimensional analysis of the vascular system in the rat spinal cord with scanning electron microscopy of vascular corrosion casts. Part 2: Acute spinal cord injury. Neurosurgery 1993;33:285-291.

39. Casella GT, Marcillo A, Bunge MB, Wood PM. New vascular tissue rapidly replaces neural parenchyma and vessels destroyed by a contusion injury to the rat spinal cord. Exp Neurol 2002;173:63-76.

40. Hall ED. Inhibition of lipid peroxidation in central nervous system trauma and ischemia. J Neurol Sci 1995;134(suppl):79-83.

41. Whalley K, O'Neill P, Ferretti P. Changes in response to spinal cord injury with development: vascularization, hemorrhage and apoptosis. Neuroscience 2006;137:821-832.

42. Lin Y, Vreman HJ, Wong RJ, Tjoa T, Yamauchi T, NobleHaeusslein LJ. Heme oxygenase-1 stabilizes the blood-spinal cord barrier and limits oxidative stress and white matter damage in the acutely injured murine spinal cord. J Cereb Blood Flow Metab 2007;27:1010-1021.

43. Hall ED, Braughler JM. Role of lipid peroxidation in post-traumatic spinal cord degeneration: a review. Cent Nerv Syst Trauma 1986;3:281-294.

44. Demopoulos HB, Flamm ES, Seligman ML, Pietronigro DD, Tomasula J, DeCrescito V. Further studies on free-radical pathology in the major central nervous system disorders: effect of very high doses of methylprednisolone on the functional outcome, morphology, and chemistry of experimental spinal cord impact injury. Can J Physiol Pharmacol 1982;60:1415-1424.

45. Giancotti FG, Ruoslahti E. Integrin signaling. Science 1999;285: $1028-1032$.

46. Hynes RO. Integrins: versatility, modulation, and signaling in cell adhesion. Cell 1992;69:11-25.

47. Goodman JH, Bingham WG Jr., Hunt WE. Platelet aggregation in experimental spinal cord injury. Ultrastructural observations. ArchNeurol 1979;36:197-201.

48. Brooks PC, Clark RA, Cheresh DA. Requirement of vascular integrin alpha $\mathrm{v}$ beta 3 for angiogenesis. Science 1994;264:569571.

49. Ritz MF, Graumann U, Gutierrez B, Hausmann O. Traumatic spinal cord injury alters angiogenic factors and TGF-betal that may affect vascular recovery. Curr Neurovasc Res 2010;7:301-310.

50. Mochizuki N. Vascular integrity mediated by vascular endothelial cadherin and regulated by sphingosine 1-phosphate and angiopoietin-1. Circ J 2009;73:2183-2191.

51. Nambu H, Nambu R, Oshima Y, et al. Angiopoietin 1 inhibits ocular neovascularization and breakdown of the blood-retinal barrier. Gene Ther 2004;11:865-873.

52. Carmeliet P. Angiogenesis in health and disease. Nat Med 2003;9:653-660.

53. Zhang ZG, Zhang L, Croll SD, Chopp M. Angiopoietin-1 reduces cerebral blood vessel leakage and ischemic lesion volume after focal cerebral embolic ischemia in mice. Neuroscience 2002;113: 683-687.

54. Uemura A, Ogawa M, Hirashima $M$, et al. Recombinant angiopoietin-1 restores higher-order architecture of growing blood vessels in mice in the absence of mural cells. J Clin Invest 2002;110:1619-1628.

55. Gale NW, Thurston G, Davis S, et al. Complementary and coordinated roles of the VEGFs and angiopoietins during normal and pathologic vascular formation. Cold Spring Harb Symp Quant Biol 2002;67:267-273.

56. Thurston G, Wang Q, Baffert F, et al. Angiopoietin 1 causes vessel enlargement, without angiogenic sprouting, during a critical developmental period. Development 2005;132:3317-3326.

57. Thurston G, Rudge JS, Ioffe E, et al. Angiopoietin-1 protects the adult vasculature against plasma leakage. NatMed 2000;6:460-463.

58. Thurston G, Suri C, Smith K, et al. Leakage-resistant blood vessels in mice transgenically overexpressing angiopoietin- 1 . Science 1999;286:2511-2514 
59. Lobov IB, Brooks PC, Lang RA. Angiopoietin-2 displays VEGFdependent modulation of capillary structure and endothelial cell survival in vivo. Proc Natl Acad Sci USA 2002;99:11205-11210.

60. Beggs JL, Waggener JD. Microvascular regeneration following spinal cord injury: the growth sequence and permeability properties of new vessels. Adv Neurol 1979;22:191-206.

61. Noble LJ, Mautes AE, Hall JJ. Characterization of the microvascular glycocalyx in normal and injured spinal cord in the rat. $\mathrm{J}$ Comp Neurol 1996;376:542-556.

62. Popovich PG, Horner PJ, Mullin BB, Stokes BT. A quantitative spatial analysis of the blood-spinal cord barrier. I. Permeability changes after experimental spinal contusion injury. Exp Neurol 1996;142:258-275.

63. del Zoppo GJ. Inflammationd and the neurovascular unit in the setting of focal cerebral ischemia. Neuroscience 2009;158:972982.

64. Guo S, Kim WJ, Lok J, et al. Neuroprotection via matrix-trophic coupling between cerebral endothelial cells and neurons. Proc Natl Acad Sci U S A 2008:105:7582-7587.

65. Dore-Duffy P. Pericytes: pluripotent cells of the blood brain barrier. Curr Pharm Des 2008;14:1581-1593

66. Bell RD, Winkler EA, Sagare AP, et al. Pericytes control key neurovascular functions and neuronal phenotype in the adult brain and during brain aging. Neuron 2010;68:409-427.

67. Armulik A, Genove G, Mae M, et al. Pericytes regulate the bloodbrain barrier. Nature 2010;468:557-561.

68. Daneman R, Zhou L, Kebede AA, Barres BA. Pericytes are required for blood-brain barrier integrity during embryogenesis. Nature 2010;468:562-566.

69. Dore-Duffy P, Owen C, Balabanov R, Murphy S, Beaumont T, Rafols JA. Pericyte migration from the vascular wall in response to traumatic brain injury. Microvasc Res 2000;60:55-69.

70. del Zoppo GJ. The neurovascular unit in the setting of stroke. J Intern Med 2010;267:156-171.

71. Abbott NJ, Patabendige AA, Dolman DE, Yusof SR, Begley DJ. Structure and function of the blood-brain barrier. Neurobiol Dis 2010;37:13-25.

72. Bazzoni G, Dejana E. Endothelial cell-to-cell junctions: molecular organization and role in vascular homeostasis. Physiol Rev 2004;84:869-901.

73. Willis CL, Leach L, Clarke GJ, Nolan CC, Ray DE. Reversible disruption of tight junction complexes in the rat blood-brain barrier, following transitory focal astrocyte loss. Glia 2004;48:1-13.

74. Smith R, Brown EH, Shum-Siu A, et al. Swim training initiated acutely after spinal cord injury is ineffective and induces extravasation in and around the epicenter. J Neurotrauma 2009;26:1017-1027.

75. Noble LJ, Donovan F, Igarashi T, Goussev S, Werb Z. Matrix metalloproteinases limit functional recovery after spinal cord injury by modulation of early vascular events. J Neurosci 2002;22:75267535.

76. Noble LJ, Wrathall JR. Distribution and time course of protein extravasation in the rat spinal cord after contusive injury. Brain Res 1989;482:57-66.

77. Nagy Z, Peters H, Huttner I. Endothelial surface charge: bloodbrain barrier opening to horseradish peroxidase induced by the polycation protamin sulfate. Acta Neuropathol Suppl 1981;7:7-9.

78. Nagy Z, Peters H, Huttner I. Charge-related alterations of the cerebral endothelium. Lab Invest 1983;49:662-671.

79. Mozer AB, Whittemore SR, Benton RL. Spinal microvascular expression of PV-1 is associated with inflammation, perivascular astrocyte loss, and diminished EC glucose transport potential in acute SCI. Curr Neurovasc Res 2010;7:238-250.

80. Furlan JC, Noonan V, Cadotte DW, Fehlings MG. Timing of decompressive surgery of spinal cord after traumatic spinal cord injury: an evidence-based examination of pre-clinical and clinical studies. J Neurotrauma 2010;27:1-29.

81. Basso DM, Beattie MS, Bresnahan JC. Graded histological and locomotor outcomes after spinal cord contusion using the NYU weight-drop device versus transection. Exp Neurol 1996;139:244256.

82. Casha S, Yu WR, Fehlings MG. Oligodendroglial apoptosis occurs along degenerating axons and is associated with FAS and p75 expression following spinal cord injury in the rat. Neuroscience 2001;103:203-218

83. Han S, Arnold SA, Sithu SD, et al. Rescuing vasculature with intravenous angiopoietin- 1 and alpha $\mathrm{v}$ beta 3 integrin peptide is protective after spinal cord injury. Brain 2010;133(Pt 4):1026-1042.

84. Donnelly DJ, Popovich PG. Inflammation and its role in neuroprotection, axonal regeneration and functional recovery after spinal cord injury. Exp Neurol 2008;209:378-388.

85. Takigawa T, Yonezawa T, Yoshitaka T, et al. Separation of the perivascular basement membrane provides a conduit for inflammatory cells in a mouse spinal cord injury model. J Neurotrauma 2010;27:739-751

86. Faulkner JR, Herrmann JE, Woo MJ, Tansey KE, Doan NB, Sofroniew MV. Reactive astrocytes protect tissue and preserve function after spinal cord injury. J Neurosci 2004;24:2143-2155.

87. Voskuhl RR, Peterson RS, Song B, et al. Reactive astrocytes form scar-like perivascular barriers to leukocytes during adaptive immune inflammation of the CNS. J Neurosci 2009;29:11511-11522.

88. Okada S, Nakamura $\mathrm{M}$, Katoh $\mathrm{H}$, et al. Conditional ablation of Stat 3 or Socs3 discloses a dual role for reactive astrocytes after spinal cord injury. Nat Med 2006;12:829-834.

89. Onose G, Anghelescu A, Muresanu DF, et al. A review of published reports on neuroprotection in spinal cord injury. Spinal Cord 2009;47:716-726.

90. Hurlbert RJ, Hamilton MG. Methylprednisolone for acute spinal cord injury: 5-year practice reversal. Can J Neurol Sci 2008;35:41-45.

91. Fehlings MG, Tator CH, Linden RD. The effect of nimodipine and dextran on axonal function and blood flow following experimental spinal cord injury. J Neurosurg 1989;71:403-416.

92. Ross IB, Tator $\mathrm{CH}$, Theriault E. Effect of nimodipine or methylprednisolone on recovery from acute experimental spinal cord injury in rats. Surg Neurol 1993;40:461-470.

93. Hall ED, Wolf DL. A pharmacological analysis of the pathophysiological mechanisms of posttraumatic spinal cord ischemia. J Neurosurg 1986;64:951-961.

94. Hall ED. Effects of the 21-aminosteroid U74006F on posttraumatic spinal cord ischemia in cats. J Neurosurg 1988;68:462-465.

95. Hall ED, McCall JM, Means ED. Therapeutic potential of the lazaroids (21-aminosteroids) in acute central nervous system trauma, ischemia and subarachnoid hemorrhage. Adv Pharmacol 1994;28:221-268.

96. Yamauchi T, Lin Y, Sharp FR, Noble-Haeusslein LJ. Hemin induces heme oxygenase- 1 in spinal cord vasculature and attenuates barrier disruption and neutrophil infiltration in the injured murine spinal cord. J Neurotrauma 2004;21:1017-1030.

97. Simard JM, Woo SK, Norenberg MD, et al. Brief suppression of Abcc8 prevents autodestruction of spinal cord after trauma. Sci Transl Med 2010;2:28ra29.

98. Simard JM, Tsymbalyuk O, Ivanov A, et al. Endothelial sulfonylurea receptor 1-regulated NC Ca-ATP channels mediate progressive hemorrhagic necrosis following spinal cord injury. J Clin Invest 2007;117:2105-2113.

99. Gerzanich V, Woo SK, Vennekens R, et al. De novo expression of Trpm4 initiates secondary hemorrhage in spinal cord injury. Nat Med 2009;15:185-191.

100. Herrera JJ, Sundberg LM, Zentilin L, Giacca M, Narayana PA. Sustained expression of vascular endothelial growth factor and angiopoietin-1 improves blood spinal cord barrier integrity and functional recovery after spinal cord injury. J Neurotrauma 2010;27:2067-2076.

101. Nakashima S, Arnold SA, Mahoney ET, et al. Small-molecule protein tyrosine phosphatase inhibition as a neuroprotective treatment after spinal cord injury in adult rats. J Neurosci 2008;28:7293-7303

102. Liu Y, Figley S, Spratt SK, et al. An engineered transcription factor which activates VEGF-A enhances recovery after spinal cord injury. Neurobiol Dis 2010;37:384-393.

103. Kim HM, Hwang DH, Lee JE, Kim SU, Kim BG. Ex vivo VEGF delivery by neural stem cells enhances proliferation of glial progenitors, angiogenesis, and tissue sparing after spinal cord injury. PLoS One 2009;4:e4987.

104. Kaneko S, Iwanami A, Nakamura M, et al. A selective Sema3A inhibitor enhances regenerative responses and functional recovery of the injured spinal cord. Nat Med 2006;12:1380-1389. 
105. Fassbender JM, Myers SA, Whittemore SR. Activating Notch signaling post-SCI modulates angiogenesis in penumbral vascular beds but does not improve hindlimb locomotor recovery. Exp Neurol 2011;227:302-313

106. Kitamura K, Iwanami A, Nakamura M, et al. Hepatocyte growth factor promotes endogenous repair and functional recovery after spinal cord injury. J Neurosci Res 2007;85:2332-2342.

107. Sasaki H, Ishikawa M, Tanaka N, et al. Administration of human peripheral blood-derived CD133+ cells accelerates functional recovery in a rat spinal cord injury model. Spine (Phila Pa 1976) 2009;34:249-254.

108. Glaser J, Gonzalez R, Perreau VM, Cotman CW, Keirstead HS. Neutralization of the chemokine CXCL10 enhances tissue sparing and angiogenesis following spinal cord injury. J Neurosci Res 2004;77:701-708.

109. Hall ED, Braughler JM, McCall JM. New pharmacological treatment of acute spinal cord trauma. J Neurotrauma 1988;5: 81-89.

110. Xiong Y, Hall ED. Pharmacological evidence for a role of peroxynitrite in the pathophysiology of spinal cord injury. Exp Neurol 2009;216:105-114.

111. Liu XM, Peyton KJ, Ensenat D, et al. Endoplasmic reticulum stress stimulates heme oxygenase-1 gene expression in vascular smooth muscle. Role in cell survival. J Biol Chem 2005;280:872-877.

112. Suri C, Jones PF, Patan S, et al. Requisite role of angiopoietin-1, a ligand for the TIE2 receptor, during embryonic angiogenesis. Cell 1996;87:1171-1180.

113. Dumont DJ, Gradwohl GJ, Fong GH, Auerbach R, Breitman ML. The endothelial-specific receptor tyrosine kinase, tek, is a member of a new subfamily of receptors. Oncogene 1993;8:1293-1301.

114. Harfouche R, Hassessian HM, Guo Y, et al. Mechanisms which mediate the antiapoptotic effects of angiopoietin-1 on endothelial cells. Microvasc Res 2002;64:135-147.

115. Fujikawa K, de de Aos Scherpenseel I, Jain SK, Presman E, Christensen RA, Varticovski L. Role of PI 3-kinase in angiopoietin-1-mediated migration and attachment-dependent survival of endothelial cells. Exp Cell Res 1999;253:663-672.

116. Kim I, Moon SO, Park SK, Chae SW, Koh GY. Angiopoietin-1 reduces VEGF-stimulated leukocyte adhesion to endothelial cells by reducing ICAM-1, VCAM-1, and E-selectin expression. Circ Res 2001;89:477-479.

117. Eliceiri BP. Integrin and growth factor receptor crosstalk. Circ Res 2001;89:1104-1110.

118. DeBusk LM, Hallahan DE, Lin PC. Akt is a major angiogenic mediator downstream of the Ang1/Tie2 signaling pathway. Exp Cell Res 2004;298:167-177.

119. Zheng DQ, Woodard AS, Tallini G, Languino LR. Substrate specificity of alpha(v)beta(3) integrin-mediated cell migration and phosphatidylinositol 3-kinase/AKT pathway activation. J Biol Chem 2000;275:24565-24574.

120. Fiedler U, Augustin HG. Angiopoietins: a link between angiogenesis and inflammation. Trends Immunol 2006;27:552-558.

121. Risau W, Flamme I. Vasculogenesis. Annu Rev Cell Dev Biol 1995;11:73-91.

122. Kurz H. Physiology of angiogenesis. J Neurooncol 2000;50:17-35.

123. Asahara T, Murohara T, Sullivan A, et al. Isolation of putative progenitor endothelial cells for angiogenesis. Science 1997;275: 964-967.

124. Asahara T, Takahashi T, Masuda H, et al. VEGF contributes to postnatal neovascularization by mobilizing bone marrow-derived endothelial progenitor cells. EMBO J 1999;18:3964-3972.

125. Jain RK, di Tomaso E, Duda DG, Loeffler JS, Sorensen AG, Batchelor TT. Angiogenesis in brain tumours. Nat Rev Neurosci 2007;8:610-622.

126. Zhang Z, Guth L. Experimental spinal cord injury: Wallerian degeneration in the dorsal column is followed by revascularization, glial proliferation, and nerve regeneration. Exp Neurol 1997;147:159-171.

127. Griffiths IR, McCulloch M, Crawford RA. Ultrastructural appearances of the spinal microvasculature between 12 hours and 5 days after impact injury. Acta Neuropathol 1978;43:205-211.

128. Baker KA, Hagg T. Developmental and injury-induced expression of alpha1beta1 and alpha6beta1 integrins in the rat spinal cord. Brain Res 2007;1130:54-66.
129. Mahoney ET, Benton RL, Maddie MA, Whittemore SR, Hagg T. ADAM8 is selectively up-regulated in endothelial cells and is associated with angiogenesis after spinal cord injury in adult mice. J Comp Neurol 2009;512:243-255.

130. Patel CB, Cohen DM, Ahobila-Vajjula P, Sundberg LM, Chacko T, Narayana PA. Effect of VEGF treatment on the blood-spinal cord barrier permeability in experimental spinal cord injury: dynamic contrast-enhanced magnetic resonance imaging. J Neurotrauma 2009;26:1005-1016.

131. van Neerven S, Joosten EA, Brook GA, et al. Repetitive intrathecal VEGF(165) treatment has limited therapeutic effects after spinal cord injury in the rat. J Neurotrauma 2010;27:1781-1791.

132. Benton RL, Whittemore SR. VEGF165 therapy exacerbates secondary damage following spinal cord injury. Neurochem Res 2003;28:1693-1703.

133. Nunes SS, Greer KA, Stiening CM, et al. Implanted microvessels progress through distinct neovascularization phenotypes. Microvasc Res 2010;79:10-20.

134. Lorquet S, Berndt S, Blacher S, et al. Soluble forms of VEGF receptor-1 and -2 promote vascular maturation via mural cell recruitment. FASEB J 2010;24:3782-3795.

135. Hamzah J, Jugold M, Kiessling F, et al. Vascular normalization in Rgs5-deficient tumours promotes immune destruction. Nature 2008;453:410-414.

136. Joutel A, Corpechot C, Ducros A, et al. Notch3 mutations in CADASIL, a hereditary adult-onset condition causing stroke and dementia. Nature 1996;383:707-710.

137. Andre C. CADASIL: pathogenesis, clinical and radiological findings and treatment. Arq Neuropsiquiatr 2010;68:287-299.

138. Gridley T. Notch signaling in vascular development and physiology. Development 2007;134:2709-2718.

139. Dvorak HF. VPF/VEGF and the angiogenic response. Semin Perinatol 2000;24:75-78.

140. Bareyre FM, Schwab ME. Inflammation, degeneration and regeneration in the injured spinal cord: insights from DNA microarrays. Trends Neurosci 2003;26:555-563.

141. Widenfalk J, Lipson A, Jubran M, et al. Vascular endothelial growth factor improves functional outcome and decreases secondary degeneration in experimental spinal cord contusion injury. Neuroscience 2003;120:951-960.

142. Karsan A. The role of notch in modeling and maintaining the vasculature. Can J Physiol Pharmacol 2005;83:14-23.

143. Liu ZJ, Shirakawa T, Li Y, et al. Regulation of Notch1 and Dll4 by vascular endothelial growth factor in arterial endothelial cells: implications for modulating arteriogenesis and angiogenesis. Mol Cell Biol 2003;23:14-25.

144. Hellstrom M, Phng LK, Hofmann JJ, et al. Dll4 signalling through Notch1 regulates formation of tip cells during angiogenesis. Nature 2007;445:776-780.

145. Roca C, Adams RH. Regulation of vascular morphogenesis by Notch signaling. Genes Dev 2007;21:2511-2524.

146. Cecchi F, Rabe DC, Bottaro DP. Targeting the HGF/Met signalling pathway in cancer. Eur J Cancer 2010;46:1260-1270.

147. Van Belle E, Witzenbichler B, Chen D, et al. Potentiated angiogenic effect of scatter factor/hepatocyte growth factor via induction of vascular endothelial growth factor: the case for paracrine amplification of angiogenesis. Circulation 1998;97:381-390.

148. Maemura M, Yoshimoto A, Tsukada Y, et al. Inhibitory effect of c-Met mutants on the formation of branching tubules by a porcine aortic endothelial cell line. Cancer Sci 2006;97:1343-1350.

149. Nagayama T, Nagayama M, Kohara S, et al. Post-ischemic delayed expression of hepatocyte growth factor and c-Met in mouse brain following focal cerebral ischemia. Brain Res 2004;999:155-166.

150. Ponce ML, Nomizu M, Kleinman HK. An angiogenic laminin site and its antagonist bind through the alpha(v)beta3 and alpha5beta 1 integrins. FASEB J 2001;15:1389-1397.

151. Ponce ML, Nomizu M, Delgado MC, et al. Identification of endothelial cell binding sites on the laminin gamma 1 chain. Circ Res 1999;84:688-694

152. Glaser J, Gonzalez R, Sadr E, Keirstead HS. Neutralization of the chemokine CXCL10 reduces apoptosis and increases axon sprouting after spinal cord injury. J Neurosci Res 2006;84:724 734. 
153. Majka M, Janowska-Wieczorek A, Ratajczak J, et al. Numerous growth factors, cytokines, and chemokines are secreted by human CD34(+) cells, myeloblasts, erythroblasts, and megakaryoblasts and regulate normal hematopoiesis in an autocrine/paracrine manner. Blood 2001;97:3075-3085.

154. Schlaeger TM, Bartunkova S, Lawitts JA, et al. Uniform vascularendothelial-cell-specific gene expression in both embryonic and adult transgenic mice. Proc Natl Acad Sci U S A 1997;94:30583063.

155. Motoike T, Loughna S, Perens E, et al. Universal GFP reporter for the study of vascular development. Genesis 2000;28:75-81.

156. Ohtsuki S, Kamiya N, Hori S, Terasaki T. Vascular endotheliumselective gene induction by Tie2 promoter/enhancer in the brain and retina of a transgenic rat. Pharm Res 2005;22:852-857.

157. De Palma M, Venneri MA, Galli R, et al. Tie2 identifies a hematopoietic lineage of proangiogenic monocytes required for tumor vessel formation and a mesenchymal population of pericyte progenitors. Cancer Cell 2005;8:211-226.

158. Arai F, Hirao A, Ohmura M, et al. Tie2/angiopoietin-1 signaling regulates hematopoietic stem cell quiescence in the bone marrow niche. Cell 2004;118:149-161.
159. Srinivas S, Watanabe T, Lin CS, et al. Cre reporter strains produced by targeted insertion of EYFP and ECFP into the ROSA26 locus. BMC Dev Biol 2001;1:4.

160. Alva JA, Zovein AC, Monvoisin A, et al. VE-Cadherin-Crerecombinase transgenic mouse: a tool for lineage analysis and gene deletion in endothelial cells. Dev Dyn 2006;235:759-767.

161. Monvoisin A, Alva JA, Hofmann JJ, Zovein AC, Lane TF, IruelaArispe ML. VE-cadherin-CreERT2 transgenic mouse: a model for inducible recombination in the endothelium. Dev Dyn 2006;235: 3413-3422.

162. Forde A, Constien R, Grone HJ, Hammerling G, Arnold B. Temporal Cre-mediated recombination exclusively in endothelial cells using Tie2 regulatory elements. Genesis 2002;33:191-197.

163. Dray C, Rougon G, Debarbieux F. Quantitative analysis by in vivo imaging of the dynamics of vascular and axonal networks in injured mouse spinal cord. Proc Natl Acad Sci USA 2009;106: 9459-9464.

164. Cao Q, Xu XM, Devries WH, et al. Functional recovery in traumatic spinal cord injury after transplantation of multineurotrophin-expressing glial-restricted precursor cells. J Neurosci 2005;25:6947-6957. 